\title{
Distribuição dos tubérculos de Tiririca (Cyperus rotundus L.) no perfil do solo e suas implicações para a conversão para agricultura orgânica de hortas urbanas
}

Distribution of tubers of Tiririca (Cyperus rotundus L.) in the soil profile and its implications for the conversion to organic agriculture of urban gardens

\section{A. Khatounian ${ }^{1}$; D. A. M. Oliveira ${ }^{1 *}$; T. M. Ferreira ${ }^{1}$; M. Dupre ${ }^{2}$; H. Merianne ${ }^{3}$}

${ }^{1}$ Departamento de Produção Vegetal, Esalq-USP, 13418-900, Piracicaba-SP, Brasil

${ }^{2}$ AgroParis Tech, F-75231 Paris Cedex 05, Paris, França

${ }^{3}$ SupAgro, 34060, Montpellier, França

*daniel.oliveira13@usp.br

(Recebido em 15 de março de 2018; aceito em 12 de setembro de 2018)

\begin{abstract}
A planta daninha Tiririca (Cyperus rotundus L.) constitui-se um dos maiores entraves para a conversão de hortas para o sistema orgânico de produção, devido principalmente à existência de estruturas subterrâneas e elevada taxa reprodutiva de forma vegetativa. O objetivo deste trabalho foi determinar a localização e distribuição dos tubérculos de $C$. rotundus no perfil do solo em hortas urbanas no município de Piracicaba, SP, buscando subsídios para a conversão das hortas para sistema orgânico de produção. O trabalho foi realizado em dez hortas situadas dentro da área urbana. Foi utilizado uma área de $0,25 \mathrm{~m}^{2}$ para retirar todo o solo do local e retirados os tubérculos de tiririca nas profundidades de 0-10 cm, $10-20 \mathrm{~cm}$ e $20-30 \mathrm{~cm}$ ou até atingir uma profundidade sem a presença de tubérculos. Os tubérculos de cada profundidade foram separados e pesados. Foi constatado que, em média, 77\% dos tubérculos estavam localizados na profundidade de $0-10 \mathrm{~cm}, 22 \%$ na profundidade de $10-20 \mathrm{~cm}$ e $1 \%$ na profundidade de $20-30 \mathrm{~cm}$. Apesar de percentualmente poucos tubérculos estarem em profundidade, estes podem garantir o repovoamento da planta daninha vegetativamente.

Palavras chave: Cyperus rotundus L.; Agricultura orgânica; Plantas infestantes.
\end{abstract}

The weed Tiririca (Cyperus rotundus L.) is one of the main obstacles for the conversion of vegetable gardens to the organic system of production, mainly due to the existence of subterranean structures and a high reproductive rate vegetatively. The objective of this work was to determine the location and distribution of tubers of $C$. rotundus in the soil profile in urban gardens in the city of Piracicaba, SP, seeking subsidies for the conversion of vegetable gardens to organic production system. The work was carried out in ten gardens located within the urban area. In these, an area of $0.25 \mathrm{~m}^{2}$ was used for remove all the soil from the site, and to remove the tubers in the depths of $0-10 \mathrm{~cm}, 10-20 \mathrm{~cm}$ and $20-30 \mathrm{~cm}$ or until reaching a depth without the presence of tubers, the tubers of each depth were separated and weighed. It was observed that on average $77 \%$ of the tubers were located in the depth of $0-10 \mathrm{~cm}, 22 \%$ in the depth of $10-20 \mathrm{~cm}$ and $1 \%$ in the depth of $20-30 \mathrm{~cm}$. Despite the fact that few tubers are in depth, these can guarantee vegetative repopulation of the weed.

Key words: Cyperus rotundus L.; Organic agriculture; Weeds.

\section{INTRODUÇÃO}

Dentre os maiores problemas para a olericultura no Brasil, especialmente para a produção de hortaliças em transição para o sistema orgânico de produção, encontra-se a planta daninha Tiririca (Cyperus rotundus L.). Segundo Lorenzi (2008) [1] é a planta daninha mais nociva e disseminada em todo o mundo, o mesmo ocorrendo na produção de hortaliças no Brasil, sendo encontrada em 
praticamente todos os climas brasileiros e, uma vez estabelecida, tem sua erradicação muito difícil de ser alcançada. Trata-se de uma planta herbácea perene, que se multiplica por sementes e principalmente vegetativamente por meio de tubérculos subterrâneos [2]. Seus tubérculos constituem a forma de dispersão mais eficiente ao longo do tempo, permanecendo dormentes por longos períodos.

Segundo Pereira (1998) [3], estas estruturas reprodutivas podem permanecer dormentes no solo por períodos de tempo que podem variar de três a cinco anos. Devido a esta própria dormência dos tubérculos, a emergência das plântulas se torna irregular, contribuindo ainda mais para a persistência dos propágulos dessa espécie no solo [4]. Seus rizomas e tubérculos podem atingir, segundo Lorenzi (2008) [1], até um metro de profundidade no solo.

A combinação das características de perene, crescimento intenso, rápida reprodução e disseminação e baixa eficiência no controle das práticas utilizadas normalmente pelos olericultores, como a capina e capina química, faz com que a espécie constitua um problema sério para a produção de hortaliças $[5,6]$.

Em sistema de produção convencional, o emprego contínuo de herbicidas tem controle na parte área da tiririca; entretanto estes normalmente não são eficientes pois a maior parte dos produtos matam apenas os tubérculos mais superficiais enquanto os tubérculos mais profundos podem fazer a população retornar [6]. Em sistema orgânico de produção, no qual é proibido o uso de herbicidas, as dificuldades de manejo da espécie se tornam ainda mais complicadas. No caso específico da agricultura urbana, na qual existe, em alguns municípios, a proibição municipal da capina química, como descrito em trabalho de Oliveira et al. (2016) [7], é grande a dificuldade de produtores de hortaliças em hortas urbanas no controle de espécies de plantas daninhas com estruturas subterrâneas. Assim, a necessidade de trabalhos de biologia desta espécie e conhecimento das quantidades e distribuição das estruturas subterrâneas torna-se cada vez maior.

O objetivo do presente trabalho foi descrever a localização e distribuição dos tubérculos de tiririca (Cyperus rotundos L.) no perfil do solo em hortas urbanas no município de Piracicaba, SP.

\section{MATERIAL E MÉTODOS}

O presente trabalho foi realizado entres os meses de maio e julho de 2014 , no município de Piracicaba (22 $42^{\prime}$ S; 47³8' O), em São Paulo, com uma altitude média de 540 m [8]. O clima, segundo classificação de Köppen, é Cwa tropical de altitude, com elevação média de $554 \mathrm{~m}$ em relação ao nível de mar, precipitação média anual de $1328 \mathrm{~mm}$ e com temperaturas anuais mínima média de $14,8^{\circ} \mathrm{C}$ e máxima média de $28,2^{\circ} \mathrm{C}$ [9]. A área do território da cidade é de $1.378,069$ $\mathrm{Km}^{2}$ e sua população é de 364.571 habitantes [10].

Para este trabalho foram selecionadas 10 hortas urbanas dentro do município de Piracicaba para a coleta de dados no inverno de 2015. Dentre elas, foram selecionadas hortas com infestação da espécie invasora em questão, constituindo um problema na percepção do agricultor e constatado em campo sua presença.

Após esta identificação inicial, foi usado um quadrado de $50 \mathrm{~cm}$ de lado $\left(0,25 \mathrm{~m}^{2}\right.$ de área) com o intuito de delimitar a área a ser cavada para a coleta dos tubérculos. Antes de cavar, foi realizada uma avaliação quantitativa dos indivíduos da espécie presente no local. Assim, para a amostragem em todas as hortas era cavado até a profundidade de $10 \mathrm{~cm}$. Todo o solo proveniente desta profundidade foi peneirado, sendo todos os tubérculos, inteiros e quebrados, alocados em recipientes plásticos devidamente identificados. Após o procedimento, o solo era retornado ao local. A mesma operação foi repetida nas profundidades de $10 \mathrm{~cm}$ a $20 \mathrm{~cm}$ e de $20 \mathrm{~cm}$ a $30 \mathrm{~cm}$, ou até atingir uma camada sem a presença de tubérculos. Os tubérculos coletados em cada camada eram alocados em recipientes plásticos e devidamente identificados. Foi realizada uma amostragem em cada horta. Os tubérculos coletados foram levados para o laboratório, onde foram limpos e separados das raízes e rizomas, foram quantificados e pesados em balança de precisão.

Em um caso, no qual a horta se localizava próxima de um edifício e um muro gerando ambiente sombreado, foi feita uma duplicação da amostragem, repetindo-se o procedimento na área sombreada e na área a pleno sol. Como estas duas amostras estavam na mesma horta e no mesmo solo, com o mesmo uso e ocupação do solo, só variando a insolação, esperava-se que uma 
diferença entre as duas amostras sugerisse a existência de um efeito da luminosidade na distribuição dos tubérculos no perfil do solo.

\section{RESULTADOS E DISCUSSÃO}

Obteve-se dois grupos de dados: o número de tubérculos e a massa destes tubérculos. Devido à dificuldade de contabilizar a quantidade dos tubérculos quebrados, será tratada aqui a distribuição dos tubérculos em função da camada do solo, usando o dado de massa destes últimos.

$\mathrm{Na}$ tabela 1 são apresentados os dados de massa totais de tubérculos para as diferentes profundidades amostradas e suas respectivas porcentagens em massa. Observando-se as médias de massas de tubérculos por profundidade, $46,70 \mathrm{~g}(0-10 \mathrm{~cm}), 13,30 \mathrm{~g}(10-20 \mathrm{~cm})$ e $0,80 \mathrm{~g}(20-30$ $\mathrm{cm})$ que existe uma redução da massa de tubérculos com o aumento da profundidade (Tabela 1), apesar de existir grande heterogeneidade entre os resultados para as mesmas camadas, que variam de acordo com a severidade da infestação.

Tabela 1. Massas de tubérculos de tiririca (Cyperus rotundus) e suas respectivas porcentagens em massa nas dez hortas amostradas ( 1 a 10), nas profundidades de $0-10 \mathrm{~cm}, 10-20 \mathrm{~cm}$ e 20 a $30 \mathrm{~cm}$, sendo as amostras 5 e 6 retiradas do mesmo local, variando apenas a condição de sombra em 5 e pleno sol em 6.

\begin{tabular}{ccccc}
\hline Amostras & $\begin{array}{c}\text { Massa de tubérculos } \\
(\mathrm{g}) \text { e percentual de } 0- \\
10 \mathrm{~cm}\end{array}$ & $\begin{array}{c}\text { Massa de tubérculos } \\
(\mathrm{g}) \text { e percentual de } 10 \\
-20 \mathrm{~cm}\end{array}$ & $\begin{array}{c}\text { Massa de tubérculos } \\
(\mathrm{g}) \text { e percentual de } \\
20-30 \mathrm{~cm}\end{array}$ & $\begin{array}{c}\text { Massa } \\
\text { total }(\mathrm{g})\end{array}$ \\
\hline 1 & $24,28(71 \%)$ & $9,22(27 \%)$ & $0,57(2 \%)$ & 34,07 \\
2 & $9,8(70 \%)$ & $4,1(29 \%)$ & $0,15(1 \%)$ & 14,05 \\
3 & $50,81(87 \%)$ & $4,1(29 \%)$ & - & 58,18 \\
4 & $47,30(89 \%)$ & $5,80(11 \%)$ & - & 53,10 \\
5 & $31,20(99 \%)$ & $0,40(1 \%)$ & - & 31,60 \\
6 & $42,9(87 \%)$ & $6,30(13 \%)$ & - & 49,20 \\
7 & $85,30(75 \%)$ & $26,10(23 \%)$ & $3,30(3 \%)$ & 114,70 \\
8 & $37,89(48 \%)$ & $35,73(47 \%)$ & $3,84(5 \%)$ & 78,45 \\
9 & $124,57(80 \%)$ & $31,32(20 \%)$ & - & 155,89 \\
10 & $13,15(69 \%)$ & $5,82(31 \%)$ & - & 18,97 \\
\hline
\end{tabular}

A partir da tabela 1, constatou-se que a porcentagem de massa total dos tubérculos se situa entre 48 e $99 \%$ na primeira camada; entre 13 e $43 \%$ na segunda camada e entre 0 e $5 \%$ na terceira camada. Apesar de existir uma heterogeneidade conforme a severidade da infestação e o manejo do solo, observa-se que oito a cada dez casos apresentados possuem mais de $70 \%$ dos tubérculos na camada de $0-10 \mathrm{~cm}$, cinco a cada dez casos possuem entre 20 e $31 \%$ dos tubérculos na camada $10-20 \mathrm{~cm}$ e sete em cada dez possuem entre 0 e $1 \%$ dos tubérculos na camada de $20-30 \mathrm{~cm}$.

Pereira (1998) [3] informa que 80\% dos tubérculos de tiririca são encontrados nos primeiros $15 \mathrm{~cm}$ de solo e $95 \%$ estão até $45 \mathrm{~cm}$ de profundidade. Nas amostras deste trabalho, os tubérculos estavam mais superficiais, o que pode ter ocorrido devido a diferentes características dos solos nos dois estudos. Jakelaitis (2003) [4] constatou maior infestação em sistemas em que houve revolvimento do solo e que a infestação por tiririca foi maior nas camadas revolvidas, sobretudo até $10 \mathrm{~cm}$ de profundidade, o que corrobora o presente estudo, que trata da produção de hortaliças.

A massa média dos tubérculos das amostragens variou de 0,17 a $0,47 \mathrm{~g}$, tendendo a diminuir com o aumento da profundidade. Contudo, essa variação na massa não alterou o quadro geral de distribuição no perfil do solo nem em massa total (Tabela 1).

A figura 1 demonstra a distribuição de tubérculos em função da profundidade do solo. 


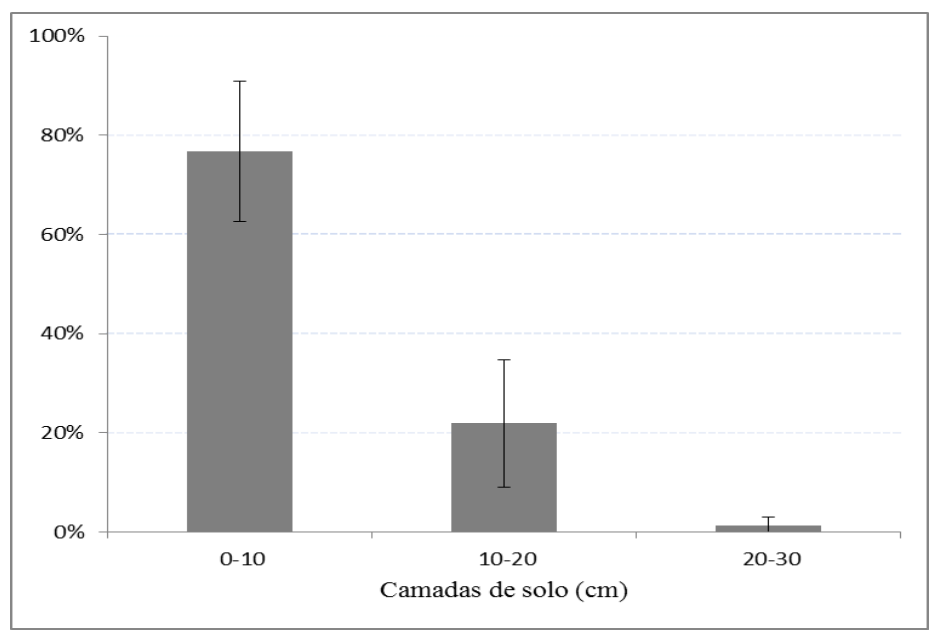

Figura 1. Porcentagem de massa de tubérculos de tiririca por camada de solo em dez hortas comerciais no município de Piracicaba, SP, 2015.

Com relação às amostras 5 (sombra) e 6 (sol), que são relativas à mesma gleba, observou-se que na sombra houve $99 \%$ dos tubérculos na camada mais superficial do solo $(0-10 \mathrm{~cm})$ e $1 \%$ na camada $10-20 \mathrm{~cm}$, enquanto no sol foram $87 \%$ na camada $0-10$ e $13 \%$ na camada de $10-20 \mathrm{~cm}$. Este trabalho não teve o objetivo de determinar a interferência de áreas de sombra e sol em relação à distribuição dos tubérculos, entretanto o resultado encontrado pode indicar a possibilidade de que áreas com sombreamento teriam uma quantidade menor de tubérculos de tiririca e uma distribuição mais superficial dos mesmos.

Em trabalho de Ascencio et al. (2005) [11], em comparação com sombra e pleno sol, a biomassa seca de folhas, raízes e tubérculos de tiririca diminuiu significativamente na sombra em relação ao sol, fato que condiz com o metabolismo de planta $\mathrm{C} 4$ que a tiririca possui, respondendo negativamente à sombra. No trabalho de Sendota e Doll (1976) [12] foi descrito que só ocorre a redução significativa do número de tubérculos de tiririca a partir de $80 \%$ de sombra e que com $100 \%$ de sombra as plantas emergiam e morriam. Apesar de grande utilidade desta informação para o controle da tiririca, esse nível de sombra é limitante também para a maioria das hortaliças, tornando estes locais mais marginais no terreno da horta urbana com menor possibilidade de ocupação para o cultivo de espécies comerciais. Entretanto, é possível se pensar em coberturas que resistam ao desenvolvimento da tiririca para que o sombreamento possa exercer algum nível de controle.

Lazo e Ascencio (2010) [13] dizem que a manipulação fisiológica da sombra pode ser usada como prática agronômica para o controle das plantas daninhas, pois a modificação temporal da quantidade e qualidade de luz gera uma composição diferente da flora infestante. Segundo Nashimoto (2001) [14], a tiririca sofre com a sombra de cultivos, entretanto, ela retorna com violência após a cobertura vegetal ser retirada.

Apenas com o trabalho em questão não é possível afirmar com certeza que a existência de sombra faz com que os tubérculos de tiririca se distribuam de forma mais superficial no terreno, entretanto existe certo indício para sugerir que novos trabalhos sejam realizados para conseguir afirmar de forma mais robusta esta informação.

Com relação ao controle da tiririca em sistema orgânico de produção de hortaliças, há um gargalo, pois, espécies que apresentam estruturas subterrâneas são minimamente afetadas pela capina [15]. Segundo Santos et al. (1997) [16], na Flórida (EUA), capinas frequentes podem exaurir as reservas subterrâneas dos tubérculos levando à morte das plantas. Entretanto, o trabalho de Horowitz (1965) [17] mostrou que remoções de parte aérea realizadas quinzenalmente não foram suficientes para erradicação da tiririca.

Neste trabalho de descrição biológica da espécie infestante em questão foi possível observar que, para as condições da metodologia, os tubérculos de tiririca se localizavam até $30 \mathrm{~cm}$ de profundidade. 
Horowitz (1972) [18] observou experimentalmente em Israel, em cultivo protegido, que a partir de um tubérculo de tiririca e após 20 meses de experimento foi produzida uma média de 1000 tubérculos $/ \mathrm{m}^{2}$. Assim, qualquer controle mecânico para ser eficiente deveria retirar os tubérculos até a profundidade máxima em que eles ocorram, para que não ocorra repovoamento do local com a planta daninha.

Um fator a mais a ser considerado está no fato de que tubérculos em maiores profundidades, apesar de ocorrerem em pequena quantidade, estão menos sujeitos a estresses, fato que lhes garante maiores chances de sobreviverem por longos períodos e servir para o repovoamento das hortas pela planta infestante [14]. Portanto, observa-se que para o produtor orgânico de hortaliças, o combate à tiririca é uma atividade que deve receber atenção constante, para que não seja necessário ocupar muita mão-de-obra com capina que pode onerar demasiadamente a produção de hortaliças, pois como observado na literatura um único tubérculo remanescente no solo pode reconstruir a população da planta daninha.

\section{CONCLUSÃO}

- Os tubérculos de tiririca (Cyperus rotundus) estão concentrados predominantemente até a profundidade de $20 \mathrm{~cm}$ dos solos em área urbana de Piracicaba, SP;

- A proporção de tubérculos decresce com a profundidade, e próximo de $70 \%$ se concentram nos primeiros $10 \mathrm{~cm}$ de profundidade $\mathrm{e}$

- Qualquer método de controle da espécie, para alcançar elevada eficiência de controle, deve alcançar os tubérculos a pelo menos $30 \mathrm{~cm}$ de profundidade.

\section{REFERÊNCIAS BIBLIOGRÁFICAS}

1. Lorenzi H. Plantas daninhas do Brasil: terrestres, aquáticas, parasitas e tóxicas. $4^{\mathrm{a}}$. ed. Nova Odessa: Instituto Plantarum; 2008.

2. Ricci MSF, Almeida DL, Fernandes MCA, Ribeiro RLD, Cantanheide MCS. Efeitos da solarização do solo na densidade populacional da tiririca e na produtividade de hortaliças sob manejo orgânico. Pesquisa Agropecuária Brasileira. 2000;35(11):2175-9.

3. Pereira W. Prevenção e controle da tiririca em áreas cultivadas com hortaliças. Brasília/DF: EmbrapaHortaliças; 1998 (Circular técnica, 15).

4. Jakelaitis A, Ferreira LR, Silva AA, Agnes EL, Miranda GV, Machado AFL. Efeitos de sistema de manejo sobre a população de tiririca. Planta Daninha. 2003;21(1):89-95, doi:10.1590/S010083582003000100011

5. Araujo LS, Cunha PCR, Silveira PM, Sousa Netto M, Oliveira FC. Potencial de cobertura do solo e supressão de tiririca (Cyperus rotundus) por resíduos culturais de plantas de cobertura. Revista Ceres. 2015;62(5):483-438, doi:10.1590/0034-737X201562050009.

6. Pereira W, Melo WF. Manejo da tiririca no sistema orgânico de produção de hortaliças. Brasília/DF: Embrapa-Hortaliças; 2008. (Circular técnica, 63).

7. Oliveira DAM, Khatounian CA, Gandara Mendes FB. Diagnóstico de hortas urbanas do município de Piracicaba, e seus entraves para a conversão para o sistema orgânico de produção. Cadernos de Agroecologia. 2015;10(3).

8. Silva Filho DF. Aplicação de videografia aérea multispectral na avaliação de floresta urbana. [Tese Doutorado em Agronomia - Produção Vegetal]. Jaboticabal: Faculdade de Ciências Agrárias e Veterinária, Universidade Estadual Paulista "Júlio de Mesquita Filho"; 2004.

9. CEPAGRI. Centro de Pesquisas Meteorológicas e Climáticas Aplicadas à Agricultura. 2015 [Acesso em: 14/04/ 2015]. Disponível em: http://www.cpa.unicamp.br/.

10. IBGE - Instituto Brasileiro de Geografia e Estatística. 2014. [Acesso em: 15/04/2015]. Disponível em: http://www.ibge.gov.br/.

11. Ascencio J, Lazo JV, Hernández E. Respuesta a la calidad y cantidad de sombra en Cyperus rotundus. Revista Saber. 2005;17:196-198.

12. Sendota FG, Doll JD. Efecto de la sombra sobre el crecimiento y desarrollo del coquito (Cyperus rotundus L.). Revista COMALFI. 1976;3:114-123.

13. Lazo JV, Ascencio J. Efecto de diferentes calidades de luz sobre el crecimiento de Cyperus rotundus. Bioagro. 2010;22(2):153-158. 
14. Nishimoto RK. Purple nutsedge tuber sprouting. Weed Biology and Management. 2001;1(4):203-208, doi: 10.1046/j.1445-6664.2001.00037.x

15. Khatounian CA, Penha LAO. Manejo de plantas invasoras na perspectiva da Agroecologia. In: Fancelli AL, Dourado Neto D (Org.). Milho: manejo e produtividade. $1^{\mathrm{a}}$. ed. Piracicaba: Esalq; 2009. v. 1, p. 3553.

16. Santos BM, Morales-Payan JP, Stall WM, Bewick TA. Influence of tuber size and shoot removal on purple nutsedge (Cyperus rotundus) regrowth. Weed science. 1997;45(5):681-683, doi:10.1017/S0043174500093334.

17. Horowitz M. Data on the biology and chemical control of the nutsedge (Cyperus rotundus) in Israel. PANS. 1965;11(4):389-416, doi:10.1080/05331856509432421.

18. Horowitz M. Effects of Frequent Clipping on Three Perennial Weeds, Cynodon dactylon (L.) Pers., Sorghum halepense (L.) Pers. and Cyperus rotundus L. Experimental Agriculture. 1972;8(3):225-34, doi:10.1017/S0014479700005299. 